\title{
MODELO DE REPRESENTAÇÃO NA LEGISLAÇÃO CUBANA
}

\author{
Geter Borges de Sousa ${ }^{1}$
}

Resumo: O objetivo do artigo é estudar como se organiza o Estado cubano, a partir de sua legislação. Expõe-se um relato histórico sobre o momento de construção da atual Constituição. Apresentam-se as leis referentes ao processo eleitoral, revogação de mandatos e conselho popular. Baseamo-nos em pesquisa histórico-documental com técnica comparativa. Constatamos que o modelo de representação do Estado cubano possui um alto grau de delegação, o que o torna mais participativo que o modelo de representação do Brasil, que é fortemente marcado pela independência dos eleitos.

Palavras-chaves: Ciência Política. Cuba. Legislação Cubana. Representação e processo eleitoral.

\begin{abstract}
This paper aims to study how to organize the Cuban State, from its legislation. It is presented a historical account about the construction time of the current Constitution. It is also discussed the laws related to the electoral process, revoking of mandates and popular advice. We rely on historical and documentary research with comparative technique. Results point that the model representation of the Cuban state has a high degree of delegation, which makes it more participatory than the model representation of Brazil, which is strongly marked by the independence of the elect.
\end{abstract}

Keywords: Political Science. Cuba. Cuban Legislation. Representation and electoral process

\section{Introdução}

A democracia representativa apresenta hoje uma grande crise de legitimidade em função de vários problemas, dentre eles a acusação de não representar os interesses dos eleitores e sim de uma pequena minoria que detém o poder econômico, mediante a sua intervenção nos momentos eleitorais. Uma das alternativas de enfrentamento desse problema é a criação de instrumentos jurídicos que permitam aos eleitores interferir no processo de decisão dos seus

\footnotetext{
${ }^{1}$ Especialista em Processo Legislativo pelo Cefor - Câmara dos Deputados, e graduação em Ciências Contábeis pela Universidade Católica de Salvador. Assessor da Câmara dos Deputados, desde 2003.
} 
representantes, pois, sem tais instrumentos jurídicos, é quase impossível qualquer intervenção por parte da sociedade.

O presente estudo situa-se no campo da Ciência Política, e têm como propósito discutir temas como representação, processo eleitoral e participação popular. Para tanto, decidiu-se analisar a estrutura do Estado cubano, no que diz respeito ao Poder Legislativo e Executivo ${ }^{2}$, pois ela traz aparentemente um modelo de representação que possibilita a participação e controle dos eleitos por parte da população. Acreditamos que essa estrutura leal é singular e poderia contribuir para o aperfeiçoamento do modelo de representação do Brasil.

Esse artigo foi elaborado com base em pesquisa documental, focada na legislação cubana, que buscou levantar como o seu Estado está estruturado em termos legais. Observamos na legislação que o Partido Comunista Cubano não interfere no processo decisório e nem eleitoral. O seu papel real no funcionamento do Estado cubano não foi objeto da pesquisa. Existem muitas polêmicas em torno de Cuba e a efetividade de sua legislação é uma delas. Para alguns, Cuba é a maior democracia da história da humanidade e para outros se trata de uma grande ditadura. A pesquisa analisou tão somente a legislação cubana, sem avaliar sua efetividade e eficácia.

\section{Cuba e a nova Constituição Socialista}

Cuba é um país pequeno, um arquipélago de 110.922 quilômetros quadrados e com poucos recursos naturais. Foi colonizado pelos espanhóis, que o exploraram até 1898. Tem todas as características históricas e culturais dos países latino-americanos.

A Revolução Cubana (1959) foi resultado de um movimento guerrilheiro que lutou contra a ditadura do governo de Fulgêncio Batista. Em função disso, no primeiro ano, a gestão do governo estava influenciada pelas táticas guerrilheiras como forma de administração estatal. O livre arbítrio dos dirigentes era a maneira de solucionar os problemas concretos do país. Um ano depois, ficou claro que era necessário administrar a máquina pública de forma racional e foram utilizadas técnicas de planificação utilizadas nos países socialistas. A falta de quadros médios, ou seja lideranças intermediárias, explicava a utilização de um conceito centralizador, criando o chamado "burocratismo" (Harnecker, 197?, p. 40).

Em 1970, havia sido estabelecida uma meta de produção nacional de 10 milhões de toneladas de alimentos, o que representaria um aumento significativo. Como disse Raúl Castro, foram propostos "cifras bastante ambiciosas naquelas circunstâncias, o que trouxe algumas consequências negativas que foram analisadas ampla e profundamente pelo companheiro Fidel" (Harnecker, 197?, p. 22). O fracasso da meta de safra dos 10 milhões tornou-se um ponto de transformação importante no desenvolvimento da Revolução cubana, devido ao processo

\footnotetext{
${ }^{2}$ O Poder Judiciário cubano não foi objeto de nossa análise, apesar de possuir elementos de participação como pode ser observado na Ley de los Tribunales Populares, Ley 82.
} 
autocrítico e de reflexão a respeito dos pontos fracos, sobre os quais deveria se concentrar a ação da direção política e do povo. Durante os últimos meses de 1970, todo o ano de 1971 e os primeiro meses de 1972, um esforço foi desenvolvido no sentido de equacionar as atividades econômicas prejudicadas, revitalizar as organizações de massas e promover uma maior participação das massas nos assuntos ligados à produção. Essas ações propiciaram avanço no terreno econômico, resultando na primeira experiência cubana de participação do povo na gestão do Estado, que foi a experiência do chamado Poder Popular em Matanzas, em 1974 (Harnecker, 197?, p. 24).

Os órgãos do Poder Popular ganharam a atribuição legal de exercer o governo, administrar entidades econômicas de produção e serviços, empreender construções e reparações, e em geral, desenvolver as atividades requeridas para satisfazer necessidades econômicas, culturais, recreativas e educacionais da coletividade na área geográfica em que exerçam a sua competência. Com essas atribuições, o Poder Popular passou a assumir as escolas, as policlínicas, os hospitais, as instalações desportivas, os cinemas, a produção de carne, frutas, vegetais, os serviços de gastronomia, as padarias, tinturarias, o serviço de táxis, a reparação de estradas locais, dentre outras. Em 2 de janeiro de 1974, Raúl Castro afirmava:

Estamos convencidos de que na medida em que as massas participem dos assuntos do Estado, se tornará mais efetiva a luta contra toda a manifestação de burocratismo, estarão melhor atendidas as necessidades da população e da comunidade e o Estado revolucionário será mais forte, mais democrático, mais sólido (Harnecker, 197?, p. 41).

A participação das massas na gestão estatal nos órgãos de Poder Popular deveria substituir o centralismo burocrático pelo centralismo democrático, por meio dos seguintes mecanismos:

a) eleição pela própria base daqueles que vão cumprir funções no aparelho do Estado nos diversos níveis da vida nacional;

b) prestação periódica de contas dos membros da comunidade eleitos como delegados ou como dirigentes dos Comitês Executivos, perante quem os elegeu;

c) possibilidade dos eleitores de revogar o mandato dos delegados se estes não cumprirem as tarefas que os eleitores lhes encomendaram.

A necessidade de uma nova Constituição foi percebida em função da construção do Poder Popular. Uma Comissão Redatora do Partido e Governo foi organizada com a participação de 20 membros, em 22 de outubro de 1974, sendo dirigida por Blas Roca. Durante os meses de maio e junho de 1975, os cubanos discutiram e aprovaram em mais de 168 mil assembleias o Anteprojeto da Constituição Socialista.

Em julho de 1975, a comissão concluiu o processo de tabulação das propostas realizadas pelas massas durantes os debates e submeteu ao primeiro congresso do Partido, no 
mesmo ano, que deliberou pela realização de um referendo nacional para aprovação final. Quase sete meses depois, a nova Constituição Socialista foi submetida ao referendo em 15 de fevereiro de 1976, com participação de $98 \%$ da população cubana maior de 16 anos, sendo que foi aprovada por $97,7 \%$ destes. Em ato público e solene foi proclamada no dia 24 do mesmo mês.

\section{Participação na Constituição Cubana}

Nesse tópico iremos apresentar alguns dispositivos da Constituição da República Cubana $(\mathrm{CRC})^{3}$ que estabelecem a participação popular. O primeiro Capítulo da Constituição fala sobre os "Fundamentos Políticos, Sociais e Econômicos do Estado", ficando estabelecido o tradicional mandamento do povo como detentor de todo o poder do Estado:

Artigo 3. - Na República de Cuba a soberania reside no povo, de quem emana todo o poder do Estado. Esse poder é exercido diretamente ou por meio das Assembleias do Poder Popular e demais órgãos do Estado que deles se derivam, na forma e segundo as normas fixadas pela Constituição e pelas leis. $[\ldots]$

O mesmo pode ser observado na Constituição da República Federativa do Brasil (CRFB) quando declara que "todo o poder emana do povo, que o exerce por meio de representantes eleitos ou diretamente" $\left(\right.$ art. $\left.1^{\circ}\right)$.

O Capítulo IX da Constituição cubana estabelece os "Princípios de Organização e Funcionamento dos Órgãos Estatais", enfatizando a eleição dos cargos representativos, a obrigação de prestação de contas e a revogação dos cargos a qualquer momento (Sousa, 2009, p. 21).

Os "Órgãos Superiores do Poder Popular" de Cuba são regulados constitucionalmente pelo Capítulo X. A “Assembleia Nacional do Poder Popular” é o órgão supremo do poder do Estado cubano, com a atribuição de expressar e representar a vontade soberana de todo o povo (CRC, art. 69). É o único órgão constituinte e legislativo da República (CRC, art. 70), e é formada por deputados eleitos por voto livre, direto e secreto (CRC, art. 71), para um mandato de cinco anos (CRC, art. 72).

Os deputados cubanos não recebem benefício econômico ou qualquer privilégio por sua condição. Eles continuam exercendo suas atividades profissionais no centro de trabalho ao qual estão ligados e recebendo o mesmo salário sem qualquer acréscimos financeiro por terem sido eleitos (CRC, art.82).

O Capítulo XII dispõe sobre os "Órgãos Locais do Poder Popular". Cuba se divide em províncias, que equivaleria aos estados brasileiros e tais províncias de dividem em municípios (CRC, art. 102). Para cada província e município existe uma Assembleia do Poder Popular Provincial e Municipal, com a atribuição de dirigir as entidades econômicas, de produção e de

3 As traduções da Constituição da República Cubana (CRC) foram feitas pelo autor. 
serviços. As Assembleias Locais do Poder Popular se apoiam nos Conselhos Populares e na ampla participação do povo (CRC, art. 103).

Os Conselhos Populares são constituídos nas vilas, bairros, povoados e áreas rurais, e são formados por delegados. As eleições são organizadas por circunscrição que é uma determinada área geográfica. Os Conselhos Populares são devidamente empoderados para o exercício de suas funções. Representam os órgãos do Poder Popular municipal, provincial e nacional na localidade (CRC, art. 104). Trata-se de um espaço que promove a capacidade de participação da população como iremos ver um pouco mais no tópico 5.

\section{Processo Eleitoral Cubano}

A descrição do processo eleitoral é fundamental para compreensão da estrutura do Estado cubano. Nesse tópico apresentaremos um pouco da legislação infraconstitucional que ordena o processo eleitoral cubano, definido pela Lei número 72 (Lei 72$)^{4}$, votada na Assembleia Nacional em 29 de outubro de 1992. Relataremos como as comissões eleitorais devem operacionalizar todo o processo. Apresentaremos as Comissões de Candidaturas que são responsáveis pela escolha de pré-candidatos, nomeados diretamente pelo povo ou pelas Assembleias. Veremos também o que está disposto na legislação para os processos de eleição do Conselho de Estado. ${ }^{5}$

\subsection{Comissões Eleitorais}

Para organizar as eleições em Cuba, a legislação prevê que um dos primeiros passos deve ser dado pelo Conselho de Estado que tem o poder de designar uma Comissão Eleitoral Nacional (Lei 72, art. 21), formada por um Presidente, um Vice-presidente, um Secretário e quatorze vogais (Lei 72, art. 20). Esta Comissão tem a tarefa de designar os integrantes das Comissões Eleitorais Provinciais e Municipais (Lei 72, art. 22, d). Os membros das Comissões Eleitorais das Circunscrições são designados pela Comissão Eleitoral Municipal (Lei 72, art. 29). As eleições são conduzidas na ponta pelas Comissões Eleitorais da Circunscrição. As suas atribuições são relacionadas no artigo 30 (Sousa, 2009, p. 30).

\subsection{Comissões de Candidaturas}

Com o objetivo de elaborar e apresentar as propostas de candidaturas a delegados das Assembleias Provinciais, Municipais e a Deputados da Assembleia Nacional do Poder Popular, dentre outros cargos, a legislação prevê a criação de Comissões de Candidaturas Nacional,

\footnotetext{
$4 \quad$ As traduções da Lei eleitoral número 72 (Lei 72) foram feitas pelo autor.

5 Estatísticas do processo eleitoral cubano desde 1979 até 2007 podem ser obtidas no Anuario Estadístico de Cuba 2008.
} 
Provinciais e Municipais (Lei 72, art. 67). Elas devem ser formadas por representantes da Central de Trabalhadores de Cuba, dos Comitês de Defesa da Revolução, da Federação de Mulheres Cubanas, da Associação Nacional de Pequenos Agricultores, da Federação Estudantil Universitária e da Federação de Estudantes de Ensino Médio, designados por suas respectivas direções nacionais, provinciais e municipais (Lei 72, art. 68), e presidida por um representante da Central de Trabalhadores de Cuba (Lei 72, art. 69). As atribuições das Comissões constam nos artigos 73, 75 e 77 da Lei 72 (Sousa, 2009, p. 31).

\subsection{Escolha dos Candidatos a Delegados Municipais}

As Comissões Eleitorais das Circunscrições devem elaborar proposta de divisão da circunscrição em até oito Áreas de Nomeação e apresentar para apreciação da Comissão Eleitoral Municipal. Possuem também as atribuições de convocar e presidir as Assembleias Gerais de Eleitores, que são realizadas em cada Área de Nomeação, para a escolha dos candidatos a delegados Municipais (Lei 72, art. 78 e 79).

Para iniciar as Assembleias de Nomeação a Comissão deve verificar previamente a presença massiva dos eleitores da área (Lei 72, art. 80). Todos os eleitores participantes têm o direito de propor candidatos a delegados municipais. Será nomeado aquele que obtiver o maior número de votos. Cada área pode nomear somente um candidato (Lei 72, art. 81). Mais de uma área de uma mesma circunscrição pode nomear o mesmo candidato, mas é necessária a nomeação de pelo menos dois candidatos por circunscrição. Se todas as áreas de uma circunscrição nomearem o mesmo candidato, a última assembleia deve nomear outro candidato. Quando se organiza apenas uma assembleia, dois nomes são escolhidos (Lei 72, art. 82). Os requisitos e procedimentos para nomeação dos candidatos são relacionados no artigo 83 (Sousa, 2009, p. 33). Os membros da Comissão Eleitoral da Circunscrição têm vinte e quatro horas para elaboração da ata da assembleia de nomeação (Lei 72, art. 84).

\subsection{Escolha dos Pré-Candidatos a Delegados Provinciais e a Deputados}

As Comissões de Candidaturas Provinciais e a Nacional primeiro devem elaborar propostas de Pré-Candidatura para os cargos de delegados das Assembleias Provinciais e Deputados da Assembleia Nacional. As propostas serão apresentadas para apreciação as Assembleias Municipais do Poder Popular. É possível ser candidato a mais de uma assembleia e quando eleito, pode-se exercer os cargos simultaneamente (Lei 72, art. 85).

Para formação das propostas de pré-candidaturas, serão considerados:

a) os delegados indicados pela Comissões de Candidatura Municipal;

b) os cidadãos indicados pelas Comissões de Candidaturas Municipais e Provinciais; 
c) as indicações de cidadãos feita pela Comissão de Candidaturas Nacional (Lei 72, art. 86).

As comissões devem consultar, na medida do possível, as instituições, organizações e centro de trabalhos, que acham pertinentes, bem como as opiniões dos delegados municipais. $\mathrm{O}$ número de delegados Municipais selecionados como pré-candidatos para as Assembleias Provinciais e para Deputados da Assembleia Nacional não pode ultrapassar a cinquenta por cento do total de pré-candidatos nos municípios (Lei 72, art. 87). O número total de précandidatos deve ser de no mínimo o dobro do número das vagas de cada município (Lei 72, art. 89).

Passando pela aprovação das Comissões de Candidaturas e das Eleitorais Provinciais e a Nacional, as proposta de pré-candidaturas dos delegados provinciais e dos deputados serão encaminhadas para as Comissões de Candidaturas Municipais, que as apresentarão nas Assembleias Municipais (Lei 72, art. 88).

\subsection{Nomeação de Candidatos a Delegados Provinciais e a Deputados}

A nomeação efetiva dos candidatos será feita pela Assembleia Municipal do Poder Popular. Ela pode aprovar ou recusar um ou todos os pré-candidatos apresentados e nesses casos as Comissões de Candidaturas terão que apresentar outros pré-candidatos (Lei 72, art. 92). O limite máximo, para escolha de candidatos entre os delegados é de cinquenta por cento do número total de candidatos (Lei 72, art. 93).

Depois de constituída as Assembleias Municipais para o novo mandato, o Conselho de Estado fixará data de sessão extraordinária para nomeação dos candidatos para os seus cargos, com o mínimo de quarenta e cinco dias de antecedência da data da eleição (lei 72, art. 94).

Na sessão, a abertura deve ser feita pelo presidente de cada Assembleia Municipal, que cede a palavra ao presidente da Comissão de Candidaturas Municipal, para apresentação da proposta de pré-candidaturas para delegados da Assembleia Provincial e para Deputados da Assembleia Nacional (Lei 72, art. 95). Primeiro deve ser apresentada a proposta de delegados e a exposição da justificativa. Em seguida, o presidente da Assembleia Municipal abrirá a discussão para que os delegados, que podem deliberar pela exclusões de nomes propostos, se aprovado por voto da maioria presente na sessão. No caso de exclusão, a Comissão de Candidaturas Municipal apresentará uma nova proposta. O mesmo acontece para a proposta de deputados (Lei 72, art. 96). Concluída a sessão, o presidente da Assembleia deve entregar para o presidente da Comissão Eleitoral a ata onde consta o nome dos candidatos (Lei 72, art. 97). No prazo máximo de setenta e duas horas, o presidente da Comissão Eleitoral Municipal informará para a Comissão Eleitoral Provincial a relação de candidatos nominados (Lei 72, art. 98). 


\subsection{Eleição}

Para se vencer uma eleição para delegado da Assembleia Municipal, é necessário que se tenha obtido mais da metade dos votos válidos na circunscrição. Caso não ocorra, a Comissão Eleitoral da Circunscrição organizará uma nova eleição em dez dias, com os dois candidatos mais votados (Lei 72, art. 120).

A Comissão Eleitoral da Circunscrição realizará a apuração da votação dos delegados para a Assembleia Provincial e dos Deputados da Assembleia Nacional, e enviará para a Comissão Eleitoral Municipal (Lei 72, art. 122). Serão considerados eleitos os candidatos que tiverem obtidos mais da metade dos votos válidos do Município (Lei 72, art. 124). O artigo 125 orienta os procedimentos nos casos de permanecer cargos vagos (Sousa, 2009, p. 36).

\subsection{Eleição do Conselho de Estado}

Para eleição do Conselho de Estado, a Comissão de Candidaturas Nacional deve apresentar proposta para Presidente, Primeiro Vice-presidente, os Vice-presidentes, o Secretário e os demais membros. Os candidatos serão selecionados entre os Deputados da Assembleia Nacional (Lei 72, art. 143). O Presidente da Assembleia Nacional abrirá para possibilidade de modificação que pode ser total ou parcial da proposta, desde que aprovada pela maioria dos presentes (Lei 72, art. 144). Logo após a eleição, os membros do Conselho de Estado devem tomar posse (Lei 72, art. 145).

\section{Revogação de mandatos de eleitos aos órgãos do poder popular de Cuba}

No legislação cubana, um dos principais elementos de controle dos eleitores sobre os mandatos é a possibilidade de revogação. O processo de revogação consta na lei número 89 (Lei 89) ${ }^{6}$, publicada na Gaceta Oficial de La República de Cuba, em 23 de setembro de 1999. Ela abrange tanto os mandatos conferidos por eleitores, quanto os outorgados pela assembleia correspondente (Lei 89, art. 1). A revogação é independente de qualquer outro procedimento penal, civil, administrativo ou trabalhista (Lei 89, art. 2) e envolve:

a) delegados, presidentes e vice-presidentes das assembleias municipais e provinciais;

b) deputados, presidente, vice-presidente e secretário da Assembleia Nacional;

c) membros do Conselho de Estado (Lei 89, art. 3).

Enquanto a revogação do mandato não for aprovada, o mandatário será mantido no cargo, mas o Conselho de Estado poderá deliberar por suspensão provisória em casos graves, até que se conclua o processo (Lei 89, art. 4). O mandato poderá ser revogado caso tenha

\footnotetext{
6 As traduções da lei da revogação do mandato dos eleitos aos órgãos do poder popular (Lei 89)
} foram feitas pelo autor. 
ocorrido repetidos descumprimentos das suas obrigações, fatos que provoquem $\mathrm{o}$ desmerecimento de bom conceito público, ou conduta incompatível com a honra de representante do povo em um órgão do Poder Popular (Lei 89, art. 5).

Os atores que poderão solicitar o início de um processo de revogação são determinados no artigo 7 da Lei 89 (Sousa, 2009, p. 40). Cada caso possui um procedimento específico. A seguir relacionamos os casos possíveis:

a) Revogação do mandato de delegado municipal proposto por outro delegado).

b) Revogação do mandato de delegado municipal proposto por vinte e cinco por cento dos eleitores.

c) Revogação do mandato de delegado provincial.

d) Revogação do mandato de deputado .

e) Revogação do mandato de presidente e vice-presidente da assembleia municipal.

f) Revogação do mandato de presidente e vice-presidente da assembleia provincial e da Assembleia Nacional.

g) Revogação do mandato de membro do Conselho de Estado (Sousa, 2009, p. 42-45).

\section{Conselhos Populares}

Os Conselhos Populares são os órgãos do poder popular que melhor expressam a participação do povo no Estado cubano. A Lei número 91 (Lei 91)7, publicada na Gaceta Oficial de La Republica de Cuba, em 25 de Julho de 2000, regula a organização e as atribuições dos Conselhos Populares, sendo definido pelos artigos abaixo:

Artigo 2. O Conselho Popular é um órgão do Poder Popular, local, de caráter representativo, investido da mais alta autoridade para o desempenho de suas funções. Compreendendo certa demarcação territorial, apoia a Assembleia Municipal do Poder Popular no exercício de suas atribuições e facilita o melhor conhecimento e assistência das necessidades e interesses da população de sua área de ação.

Artigo 3. O Conselho Popular não constitui uma instância intermediaria para fins de divisão político-administrativa e nem dispõe de estrutura administrativa subordinada. Exerce as atribuições e funções que lhe outorgam a Constituição e as leis, com a participação ativa do povo no interesse da comunidade e de toda a sociedade; representa a demarcação onde atua e é, ás vezes, representante do órgão do Poder Popular municipal, provincial e nacional ante a população, as instituições e entidades nela radicadas (Lei 91).

Os Conselhos Populares devem contribuir dando conhecimento para a assembleia municipal sobre as atividades econômicas, produtivas e de serviços (Lei 91, art. 4). Eles serão criados em bairros, povoados, zonas rurais com no mínimo cinco circunscrições, podendo ser 
menos em casos excepcionais (Lei 91, art. 6). Serão formados pelos delegados eleitos nessas circunscrições, por representantes das organizações de massa e das instituições mais importantes da área (Lei 91, art. 9).

A Lei 91 delibera ainda sobre a participação popular, o controle e fiscalização sobre as entidades estatais, a coordenação de ações e de cooperação, as relações com as administrações, e o funcionamento dos Conselhos Populares (Sousa, 2009, p. 50-55).

\section{Conclusão}

Tanto a Constituição brasileira como a cubana se legitimam a partir da tradicional afirmação de que o povo é o detentor da soberania do Estado. A grande diferença reside na forma como essa soberania é exercida, de acordo com o ordenamento jurídico formal de cada um dos dois países.

A legislação brasileira se próxima do conceito de democracia de Schumpeter na medida em que garante total independência dos eleitos na tomada de decisões. Mesmo os instrumentos como plebiscito, referendo $^{8}$ e iniciativa popular ${ }^{9}$, são intermediados pelos eleitos, que controlam, em última instância, momento, conteúdo e forma de aplicação. Cabe ao povo brasileiro apenas "aceitar ou recusar as pessoas designadas para governá-lo", como propõe Schumpeter (1984, p. 322). Outro aspecto é que não existem alternativas de revogação de mandatos por iniciativa dos eleitores, o que poderia ser usado como forma de pressão e de influência popular sobre o processo decisório.

Em Cuba, a estrutura jurídica formal se aproxima da concepção de Rousseau quanto a regimes democráticos, mesmo levando em consideração que "se tomarmos o termo no rigor da acepção, nunca existiu verdadeira democracia, nem jamais existirá" (Rousseau, 1996, p. 83). Os mecanismos de participação e controle social sobre o Estado, independentemente de sua efetividade, são significativos na legislação cubana. Esses mecanismos se baseiam em quatro elementos chaves:

a) eleição direta de apenas uma pessoa por circunscrição, para o cargo de delegado e para outros, funcionando a reduzida área geográfica da circunscrição como fator que facilita o conhecimento da história dos candidatos e a participação popular;

\footnotetext{
8 De acordo com o art. $2^{\circ}$ da Lei $n^{\circ} 9.709$, de 18 de novembro de 1998, "plebiscito e referendo são consultas formuladas ao povo para que delibere sobre matéria de acentuada relevância, de natureza constitucional, legislativa ou administrativa"; "o plebiscito é convocado com anterioridade a ato legislativo ou administrativo, cabendo ao povo, pelo voto, aprovar ou denegar o que the tenha sido submetido"; "o referendo é convocado com posterioridade a ato legislativo ou administrativo, cumprindo ao povo a respectiva ratificação ou rejeição".

O art. 13 da Lei n $^{\circ}$ 9.709, de 1998, refere-se à iniciativa popular: "a iniciativa popular consiste na apresentação de projeto de lei à Câmara dos Deputados, subscrito por, no mínimo, um por cento do eleitorado nacional, distribuído por cinco estados, com não menos de três décimos dos eleitores de cada um deles.
} 
b) obrigatoriedade de prestação de contas dos eleitos perante seus eleitores;

c) possibilidade de revogação de mandatos por parte dos eleitores;

d) o empoderamento local através dos Conselhos Populares investidos da mais alta autoridade para o exercício de suas funções.

Esses mecanismos parecem ser bem mais avançados que os presentes na legislação brasileira no que diz respeito à garantia da efetividade da soberania do povo. É tanto mais fácil para o poder econômico influenciar decisões contrárias à vontade da maioria da população quanto maior for a independência dos representantes, justamente em função da concentração de poder nas mãos de poucos. Já no modelo proposto pela legislação cubana, essa influência é mais difícil, em função da possibilidade de ampla participação popular ao longo de todo o processo decisório. Com base nisso, acreditamos que a probabilidade de se chegar a resultados melhores, do ponto de vista da afirmação da vontade popular, é maior com a legislação cubana, apesar de não haver nenhum estudo que comprove essa afirmação, pelo simples fato de ela possibilita maior controle social.

O elemento que consideramos fundamental para a construção da democracia é a organização social fora da máquina do Estado. Rousseau (1996) aponta para o perigo do Estado usurpador e apresenta como alternativa a autoconvocação popular. Por mais democrática que seja a conformação institucional do Estado, não tira a importância da organização da sociedade fora da máquina estatal. Podemos observar em vários artigos da legislação cubana, conforme apresentado, o reconhecimento da legítima existência e da necessária participação das organizações de massa nas decisões das Assembleias do Poder Popular e do Poder Executivo. Claro que esses aspectos legais não impedem que o Estado cubano se torne usurpador, nem mesmo que tal legislação seja efetivamente observada. Por outro lado, não encontramos na legislação brasileira possibilidade de uma efetiva participação em qualquer estrutura de poder por parte de movimentos sociais. O máximo que podemos observar são os conselhos subalternos ao Poder Executivo, que adota suas políticas de governo sem a obrigatoriedade jurídica de ouvir a população ou movimentos sociais.

Como mencionamos na introdução, existem muitas polêmicas em torno de Cuba. Para alguns Cuba é a maior democracia da história da humanidade e para outros se trata de uma grande ditadura. A pesquisa analisa a legislação cubana, sem avaliar a sua efetividade e eficácia. Nesse sentido, acreditamos que a pergunta mais importante a se fazer, como desdobramento dessa pesquisa, é se de fato estaríamos caminhando para a construção de um Brasil melhor, caso os pressupostos encontrados na legislação cubana fossem incorporados pela legislação brasileira e colocados efetivamente em prática na nossa realidade. 


\section{Referências}

BRASIL, Constituição (1988). Constituição da Repúplica Federativa do Brasil. Brasília: Câmara dos Deputados. Coordenação de Publicações, 1998.

CUBA, Anuario Estadístico de Cuba 2008. Oficina Nacional de Estadísticas. La Habana, Ago 2009. Capitulo XXII, pag. 419-432. Disponível em www.one.cu/aec2008/datos/00AEC\%20publicacion\%20completa.pdf. Acesso em 17 dez. 2009.

CUBA, Constitucion (1976) Constitucion de la Republica de Cuba. Gaceta Oficial de la Republica de Cuba, La Habana, 31 jan.2003. Extraordinaria, Año CI, n. 3, p. 7. Disponível em www.gacetaoficial.cu. Acesso em: 17 dez. 2009.

CUBA, Ley n. 72 de 29 de outubro de 1992. Ley Electoral. Gaceta Oficial de la Republica de Cuba, La Habana, 2 nov.1992. Extraordinaria, Año XC, n. 9, p. 51. Disponível em www.gacetaoficial.cu. Acesso em: 17 dez. 2009.

CUBA, Ley n. 82 de 11 de julho de 1997. Ley de los Tribunales Populares. Gaceta Oficial de la Republica de Cuba, La Havana, 14 jul.1997. Extraordinaria, Año XCV, n. 8, p. 69. Disponível em www.gacetaoficial.cu. Acesso em: 17 dez. 2009.

CUBA, Ley n. 89 de 14 de setembro de 1999. Ley de Revocacion del Mandato de los Elegidos a los Organos del Poder Popular. Gaceta Oficial de la Republica de Cuba, La Habana, 23 set.1999. Edición Ordinaria , Año XCVII, n. 62, p. 1001. Disponível em www.gacetaoficial.cu. Acesso em: 17 dez. 2009.

CUBA, Ley n. 91 de 13 de julho de 2000. Ley de los Consejos Populares. Gaceta Oficial de la Republica de Cuba, La Havana, 25 jul.2000. Extraordinaria, Año XCVIII,n. 6, p. 29. Disponível em www.gacetaoficial.cu. Acesso em: 17 dez. 2009.

HARNECKER, Marta. Cuba: democracia ou ditadura? Número de Catalogo 1168 - Tradução: A. Silva - Publicado por acordo com Iniciativas Editoriais - Lisboa - Portugal - São Paulo: Global Editora e Distribuidora Ltda, 197?.

ROUSSEAU, Jean-Jacques. O contrato social. Tradução: Antônio de Pádua Danesi. $3^{\text {a }}$ edição. São Paulo: Martins Fontes, 1996.

SCHUMPETER, Joseph A. Capitalismo, socialismo e democracia. Rio de janeiro: Fundo de Cultura, 1984.

SOUSA, Geter Borges. Estrutura da Democracia Cubana. Brasília: Biblioteca Digiltal da Câmara dos Deputados, 2009. Disponível em

http://bd.camara.gov.br/bd/handle/bdcamara/5504. Acesso em: 01 mar 2011.

Artigo recebido em: 14/04/2010

Artigo aceito para publicação em: 02/06/2011 